\title{
The validity and reliability of iridology in the diagnosis of previous acute appendicitis as evi- denced by appendectomy
}

\author{
L Frank ${ }^{*}$, JT Ferreira ${ }^{+}$and J Pellow*
}

"Department of Homoeopathy, University of Johannesburg, PO Box 524, Auckland Park, 2006 South Africa and ${ }^{+}$Department of Optometry, University of Johannesburg, PO Box 524, Auckland Park, 2006 South Africa

+<jferreira@uj.ac.za>

Received 12 April 2013; revised version accepted 30 September 2013

\begin{abstract}
Iridology is defined as a photographic science that identifies pathological and functional changes within organs via biomicroscopic iris assessment for aberrant lines, spots, and discolourations. According to iridology, the iris does not reflect changes during anaesthesia, due to the drugs inhibitory effects on nerves impulses, and in cases of organ removal, it reflects the pre-surgical condition.
\end{abstract}

The profession of Homoeopathy is frequently associated with iridology and in a recent survey (2009) investigating the perceptions of Masters of Technology graduates in Homoeopathy of University of Johannesburg, iridology was highly regarded as a potential additional skill requirement for assessing the health status of the patient.

This study investigated the reliability of iridology in the diagnosis of previous acute appendicitis, as evidenced by appendectomy. A total of 60 participants took part in the study. Thirty of the 60 participants had an appendectomy due to acute appendicitis, and 30 had had no prior history of appendicitis. Each participant's right iris was documented by photography with the use of a non-mydriatic retinal camera that was reset for photographing the iris. The photographs were then randomized by an external person and no identifying data made available to the three raters. The raters included the researcher, who had little experience in iridology and two highly experienced practising iridologists. Data was obtained from the analyses of the photographs wherein the presence or absence of lesions (implying acute appendicitis) was indicated by the raters.

None of the three raters was able to show a significant success rate in identifying correctly the people with a previous history of acute appendicitis and resultant appendectomies from those who had no previous history of acute appendicitis. Therefore the outcome of this study indicated an outcome that was subject to chance.

The null hypothesis that states that appendectomy due to acute appendicitis does not manifest in corresponding lesions in the iris, is supported. It is in the opinion of the researchers that the association of iridology with homoeopathic practice may harm the credibility of the profession and that further research on iridology is needed to disprove this conviction. (S Afr Optom 2013 72(3) 127-132)

Key words: Iris, iridology, iris diagnosis, homoeopathy, appendicitis, appendectomy. 


\section{Introduction}

Iridology, also known as iris diagnosis or iridodiagnosis, is defined as a science that identifies pathological and functional changes within organs via assessing the iris for aberrant lines, spots and discolourations ${ }^{1}$. According to Jensen ${ }^{2}$ iridology is the science of establishing acute, sub-acute, chronic diseases in certain organs of the body by evaluating specific areas in the iris.

The inspection of the iris as a health indicator has existed since antiquity, but the foundation for iridology was first established ${ }^{3}$ in 1670 by Phillipi Meyers, and extrapolated upon by Ignaz Péczely in 1881 and Nils Liljequist (a Swedish homoeopath) in 1890. An American chiropractor, Bernard Jensen (1908-2002), later diagrammatically illustrated the position of specific organs, body parts and functions as manifested in the iris ${ }^{5}$.

Iridology is used worldwide and is frequently incorporated as an adjunct to existing diagnostic techniques by a wide range of complementary therapists. According to Ernst ${ }^{4}$ iridology is regarded as the most invaluable naturopathic tool in the United States of America, while in Germany $80 \%$ of the alternative health practitioners (which includes homoeopaths) use it.

The profession of Homoeopathy is frequently associated with iridology and in a recent survey by Rostovsky $e t a l^{5}$ to investigate perceptions of Masters of Technology graduates in Homoeopathy of the University of Johannesburg; iridology was highly regarded as a potential skill for assessing the health status of the patient.

There have been several studies ${ }^{6,7}$ on iridology which have proven iridology to be ineffective in the diagnosis of certain diseases, specifically cancer, gall bladder disease, kidney disease, ulcerative colitis, asthma, coronary heart disease and psoriasis ${ }^{5,6}$. Other studies though have found it useful in the diagnosis of hypertension and hearing loss ${ }^{6,8}$.

This study investigates the usefulness of iridology in determining a previous acute appendicitis as evidenced by appendectomy. This is based on the precept that exists in iridology that the iris does not reflect changes during anaesthesia, due to its inhibitory effect on nerve impulses, but in cases of organ removal, the iris reflects the pre-surgical condition ${ }^{2}$.

According to the Iridology Institute of Southern Africa ${ }^{9}$, iridology offers several advantages to health professionals in that it is:

1. Non-invasive and safe

2. Cost effective

3. Iris signs manifest before gross pathology does, thus iridology may provide information on vital processes before symptoms manifest therefore it is particularly useful in preventative care

4. It provides a valuable framework for assessing future limitations and potentials of a patient's health ${ }^{10}$.

O'Mathuna $^{10}$, however, is of the opinion that whilst iridology is harmless in terms of examination or photography of the eye, considerable damage may occur should iridology be used with the exclusion of other reliable diagnostic tools. He believes false negatives may cause patients to delay seeking treatment for serious conditions and false positives may provoke considerable and unnecessary anxiety and possibly encourage unnecessary medical interventions. Furthermore patients may waste valuable resources and risk side-effects from the herbal remedies and dietary supplements prescribed by the iridologist.

It is therefore obvious that while there is a considerable interest in this technique and some optometrists may consider iridology more particularly as a diagnostic tool, it is also clear that the validity and reliability of iridology remains to be established beyond reasonable doubt.

\section{Methodology}

This study was a randomized and controlled quantitative study, evaluated by comparative analysis. A total of 60 participants took part in the study. Participants included were either male or female, between the ages of $18-65$ years. Thirty had previously had an appendectomy due to acute appendicitis while the other 30 had no prior history of appendicitis or an appendectomy. All participants were recruited from a private optometric practice, namely at Rita Frank Optometrists. Off-site permission was 
obtained from the University of Johannesburg, as well as permission from the optometric practice to use the premises, fundus camera and to recruit from the existing extensive patient-base. Participants who were excluded from the study included individuals who suffered from any disease that may have affected the appearance of the iris, for example, connective tissue disease, neurofibromatosis, benign or malignant tumours of the iris, individuals who were on medication for glaucoma; and individuals who have had surgery on their iris and individuals who suffered from bowel disorders such as inflammatory bowel disease (Crohns disease or ulcerative colitis). Of those who had had appendectomies, participants were excluded whom had not had the procedure done as the result of an acute appendicitis. Of those who did not have appendectomies but with a positive history of appendicitis were also excluded.

Each individual who met the criteria were requested to sign a Participant Information and Consent Form and a Consent Form for Permission to Photograph the iris.

Each participant's right iris was photographed with a non-mydriatic retinal camera (Canon EOS20D), which was capable of taking either retinal or iris photographs. At least two photographs of each participant's right iris were taken, of which the best photograph was chosen by the first author for the subsequent evaluations. Eye colour and time lapse after appendectomy was also documented for adjunct investigations into iridological accuracy.

The photographs were randomized by an external person and no identifying information was made available to three raters. Rater 1 (the first author) was relatively new to the iridological method, having completed a week-long part-time basic course. The photographs were meticulously inspected for any of the typical iris signs indicative of acute appendicitis with the aid of specialized iridology software, documenting the presence or absence thereof. The software superimposes Jensen's diagram over the digital photograph, which facilitates the identification of the organ area, amongst other tools.

Both Rater 2 and 3 had been practising iridology as a diagnostic tool in their practices for 9 and 11 years, respectively. Rater 2 made use of the same iridology software to help guide his responses, whilst Rater 3 relied solely on his experience in the field. All data was recorded using a Microsoft Excel spreadsheet and submitted for analysis

\section{Results}

No rater managed to ascertain correctly whether or not an acute appendicitis and thus appendectomy was likely in the participant's history. Rater 2 was the most successful but only scoring 53\% correctly, followed by Rater 3 who scored $42 \%$ correctly and Rater 1 who only scored $40 \%$ correctly. Thus the raters overall performed poorly, with only Rater 2 scoring more than half correctly - a result more congruent with luck than certainty.

The differences in the success rates between raters were $11 \%$ between Rater 2 and Rater 3, and 13\% between Rater 2 and Rater 1, respectively. One might argue that the difference between Rater 2 and 3 was the use of the software by rater 2 or that the difference between Raters 1 and 2 may be ascribed to Rater 2's previous experience. However, both arguments are refuted when it is considered that Rater 2's relative success was still poor; after-all, Rater 3 had the most experience and performed only marginally better than the novice (Rater 1), and both Rater 1 and 2 used the same software.

Next, a more complicated model, in the form of contingency analyses (using Chi-Square tests), was done to determine the true association between rater's assessment and outcome. The level of significance was set at the $95 \%$ level $(p<0.05)$. Importantly, probabilities of being correct could be established from these models. As expected, Rater 2 had the highest probability of the raters of being correct $(p=0.60)$; Even so he had a moderate probability of scoring correctly. Rater 1 obtained a $p$ value of 0.12 and rater 3 a mere value of $p=0.20$. These results confirm that none of the raters performed well as no statistically significant association between choice and outcome of successfully selecting the participants who had an appendectomy existed for any of the raters.

Correlation coefficients were also calculated to determine the degree of agreement between raters, or in other words, to determine the extent to which raters overlapped when scoring irises, The $p$-value for the agreement between Rater 1 and 2 was 0.13 , for Rater 
1 and 3 was 0.85 , and between Rater 2 and 3 was 0.18 . Therefore none of the raters scored similarly to each other and no statistically significant relationship existed at a $95 \%$ level of confidence. What is apparent from this lack of accord is the highly individualistic approach that is employed by each rater despite some raters using the same diagnostic software. Such uncertainty raises questions regarding the validity and reliability of this technique as a diagnostic tool.

Finally, to account for other factors such as eye colour and the time lapse after appendectomy which may have exerted an influence on the raters' response, logistic regressions were determined.

\section{Eye Colour}

According to iridology, only two basic iris colours exist, blue and brown ${ }^{12}$. Also it is stated that it is not uncommon for eyes to change colour as treatment progresses to optimal health, for example, from hazel to blue ${ }^{13}$. This is not supported by medical literature, with changes in eye colour being mainly attributed to pathology in adulthood. Bodeen and Jensen ${ }^{14}$ state that blue irides are easier to analyse than brown because the iris fibers are more distinct due to the absence of iris pigmentation.

Therefore it was conjectured that eye colour might influence the ease of identification of important signs in the iris with light eyes such as blue being the easiest to identify correctly, and brown being the most difficult. In this study, the proportions of the eye colours of participants were relatively equal, with $30 \%$ blue, $35 \%$ green and $35 \%$ brown eyes. Of the participants without appendectomy, the majority had green eyes $(43 \%)$, followed by brown eyes $(40 \%)$ and blue eyes (17\%). Of the participants with appendectomy, the majority had blue eyes $(43 \%)$, followed by brown eyes $(30 \%)$ and then green eyes $(27 \%)$. Thus, when scoring for the absence of appendectomy, green eyes had a marginal advantage while blue eyes had a relative disadvantage, and when scoring present for appendectomy, blue eyes had the advantage, with other colours being relatively equal.

In the model for Rater 1 the opposite to our conjecture occurred. Although Rater 1 had a better probability for scoring correct if the participant's iris was brown, with poorer probabilities for scoring true outcomes with blue or green eyes. The $p$-value correlating eye colour and outcome was 0.42 , suggesting that no statistical association existed.

Rater 2, on the other hand, scored blue eyes more correctly, with green second and brown last but again. This was consistent with the proposed theory, although the $p$-value of 0.19 suggested no such relationship existed.

Rater 3 tended to score green eyes the most correct, followed by brown and lastly blue eyes. The $p$-value generated was, in this case, statistically significant at a $95 \%$ level of confidence, at 0.01 . It seems that, at least for Rater 3, the eye colour of the participant had a significant effect on the outcome, but also not in the way that was theorized.

\section{Time Lapse After Appendectomy}

Another factor that perhaps could influence the accuracy of responses was the extent of the time lapse that occurred after the appendectomy was performed. Here it was postulated that the more recent surgeries would have more obvious lesions in the iris. This was based on the notion that healing may still have occurred in the iris ${ }^{12}$, even though nervous relay was severed during surgery ${ }^{2}$ and therefore the iris will show the signs of appendicitis.

Forty-three percent $(43 \%)$ of the appendectomies of participants occurred within the last 10 years. Those who had an appendectomy about 11-29 years ago made up $26 \%$ of the sample while those who had the procedure done more than 30 years ago accounted for $30 \%$. From this it can be supposed that because the more recent group constituted the majority, it was more likely to have an influence on outcome but no raters had $p$-values indicating significant association between time lapse and outcome. The $p$-values were, for Raters 1, 2 and 3, 0.1, 0.19 and 0.11, respectively. Rater 1 showed no preference for any specific group, Rater 2 scored the intermediate group more correctly, whilst Rater 3 progressively scored more correct from the most recent to the largest time lapse. This was exactly the opposite of what was expected.

\section{Discussion}

Generally the results found in this study are in accordance with other studies conducted on iridology wherein the statistical significance of correctly identifying systemic disorders was also no better than chance. These included the diagnoses of gall bladder 
disease $^{11}$ and kidney disease ${ }^{15}$.

Buchanan et al. ${ }^{6}$, who studied the diagnostic accuracy of iridology in systemic disease, specifically ulcerative colitis, asthma, coronary heart disease and psoriasis; and Münstedt et al. ${ }^{16}$ concerning cancer diagnosis, also came to the same conclusion

The purpose of diagnostic testing as specified by Beers et al. ${ }^{17}$ is to help the clinician make choices by reducing ambiguity, making diagnoses or identifying patients who are at risk of developing occult disease. As is clear from this study and literature, iridology as a diagnostic tool does not really appear to meet these requirements. Iridology would rather increase uncertainty as it does not seem to provide a reliable method for the detection of disease.

The results obtained in this study on the effect of eye colour and time lapse after appendectomy also indicate the inability of iridology to successfully identify disease from iris photography.

\section{Repercussions for the Homoeopathic Profession}

$\mathrm{O}^{\prime}$ Mathuna ${ }^{11}$ is of the opinion that iridology is ultimately harmful to the patient because of its poor efficacy. As was established during this study, the likelihood of generating false positives and false negatives was considerable. The current study attempted to determine the ability of iridology to determine signs of appendicitis in patients that have had an appendectomy and therefore the correct/ incorrect diagnosis would not significantly impact on the patient health. In general though, a false negative in the diagnosis of an acute appendicitis would certainly be detrimental to the patient. A false positive may prompt unwarranted stress for the patient, not to mention the wastage of the patient's resources and perhaps unnecessary treatments. The treatment and management of the patient may take an entirely different route that may not be in the best interest of the patient.

It is the opinion of the researchers that the association of iridology with homoeopathic practice potentially may harm the credibility of the profession. Further research providing concrete evidence on some of the tenets of iridology is needed to shift the method from the realm of pseudoscience to reality.

\section{Recommendations}

There are several recommendations to be made regarding this study. First and foremost, the study attempted to establish the reliability of iridology in the diagnosis of previous acute appendicitis, as evidenced by appendectomy - this only tests one theory that exists in iridology, namely that the surgery severs the nervous feedback to the iris and therefore the lesion will still remain on the iris after surgery effectively freezing it in time ${ }^{2}$. Even iridologists are in disagreement amongst themselves with this precept and there are also a multitude of other theories pertaining to iridology that have yet to be proven or disproven.

Another problem when recruiting iridologists for this study was the lack of standardisation of training between iridologists. Training in iridology in South Africa is hugely variable and it is problematic to establish what constitutes a competent iridologist, since the training is not clearly specified or accredited.

Another issue encountered was the fact that the researcher recruited and interviewed the participants, and took and analysed the photographs. Although considerable time passed between the taking of photographs and the consequent analysis, and although the photographs were assigned new random numbers and interpreted in their new sequence without any other original identifying information, the researcher's outcome could still have been influenced, even though the researcher scored the worst among raters.

Another possible concern with the study was the fact that the raters knew that half of the participants were included as controls. This might have led to different scoring behaviour that might have otherwise been the case. Lastly, consideration must always be given to the sample size of the study. The greater the number of participants, the greater the distribution approximates the actual population.

\section{Conclusion}

This study was designed to assess the validity and reliability of iridology in the diagnosis of previous acute appendicitis, as evidenced by appendectomy. It was hypothesized that an appendectomy due to previous acute appendicitis would be represented by the typical lesion in the iris.

None of the three raters showed a significant success rate in correctly determining those with 
previous acute appendicitis from those without a positive history of this condition. Our results indicate that a correct outcome was random and subject to chance. The fact that there was noticeable variability in the raters' responses compounded the supposition that choices were random.

These results suggest that the null hypothesis, that states that appendectomy due to acute appendicitis does not manifest in a corresponding lesion in the typical organ area of the eye, is supported. It is the opinion of the researcher that the association of iridology with homoeopathic practice may possibly harm the credibility of the profession and that further research on iridology is needed to disprove this conviction.

\section{References}

1. Medow NB. Iridology uses marks on iris as windows to diagnosis. Opthalmology Times 2000 25(8) 22-24.

2. Jensen DC. Iridology: Science and Practice in the Healing Arts. Volume 2. California: Bernard Jensen Enterprises, 1982 p21, 37-39.

3. Norn M. Analysis of the iris: history and future. (Abstract). Dansk Medicinhistorisk Arbog 2003 103-117.

4. Ernst E. Iridology: not useful and potentially harmful. Archives of Opthalmology 2000 118(1) 120-121.

5. Rostovsky JD, Saunders B, Gower, N. A Survey to Investigate the Current Perceptions of Graduates of the University of Johannesburg M. Tech: Homoeopathy Programme and a Training Needs Analysis for Continued Professional Development. Unpublished dissertation. Johannesburg: University of Johannesburg, South Africa 2009.

6. NCCAM. Iridology. National Center for Complementary or Alternative Medicine.http://www.gale.cengage.com/ PeriodicalSolutions/academicOnefile.htm. 2008 Date accessed: 11/09/2010.

7. Buchanan TJ, Sutherland CJ, Strettle RJ, Terrell TJ, Pewsey A. An investigation of the relationship between anatomical features in the iris and systemic disease, with reference to iridology. Complementary Therapies in Medicine 1996 4(2) 98-102.

8. Stearn N, Swanepoel DW. Identifying hearing loss by means of iridology. African Journal of Traditional, Complementary, and Alternative Medicines 2006 4(2) 205210.

9. IISA. Iridology Institute of Southern Africa. http://www. iridology.co.za 2011 Date accessed: 1/10/2011

10. Jensen DC. The Science and Practice of Iridology. 16th Edition. California: Bernard Jensen Enterprises, 1989 p135, 352 .

11. O'Mathuna, DP. Iridology as a diagnostic tool. Alternative Medicine Alert. http://www.gale.cengage.
com/PeriodicalSolutions/academicOnefile.htm 2003 Date accessed: 11/09/2010.

12. Jenks JD. The Eyes Have It: An Introduction To Iridology. USA: J. D. Jenks, 1981 pp5 - 14.

13. Bamer DR. Practical Iridology and Sclerology. Utah: Woodland Publishing, 1996 pp33, 54-66.

14. Bodeen DV, Jensen B. Visions of Health: Understanding Iridology. USA: Avery, 1992 pp56-58.

15. Simon, A, Worthen DM, Mitas JA. An evaluation of iridology. Journal of the American Medical Association 1979 242(13) 1385-1389.

16. Münstedt K, El-Safadi S, Brück F, Zygmunt M, Hackethal A, Tinneberg H. Can iridology detect susceptibility to cancer? A prospective case-controlled study. The Journal of Alternative and Complementary Medicine 2005 11(3) 515519.

17. Beers MH, Porter RS, Jones TV, Kaplan JL, Berkwits M. (Editors). The Merck Manual of Diagnosis and Therapy. USA: Merck Research Laboratories, 2006 pp101-102. 